\title{
Design and Development of Floor Cleaner Robot (Automatic and Manual)
}

\author{
Manreet Kaur \\ Centre for Development of \\ Advanced Computing, Mohali
}

\author{
Preeti Abrol \\ Centre for Development of \\ Advanced Computing, Mohali
}

\begin{abstract}
Manual work is taken over the robot technology and many of the related robot appliances are being used extensively also. Here represents the technology that proposed the working of robot for Floor cleaning. This floor cleaner robot can work in any of two modes i.e. "Automatic and Manual". All hardware and software operations are controlled by AT89S52 microcontroller. This robot can perform sweeping and mopping task. RF modules have been used for wireless communication between remote (manual mode) and robot and having range $50 \mathrm{~m}$. This robot is incorporated with IR sensor for obstacle detection and automatic water sprayer pump. Four motors are used, two for cleaning, one for water pump and one for wheels. Dual relay circuit used to drive the motors one for water pump and another for cleaner. In previous work, there was no automatic water sprayer used and works only in automatic mode. In the automatic mode robot control all the operations itself and change the lane in case of hurdle detection and moves back. In the manual mode, the keypad is used to perform the expected task and to operate robot. In manual mode, RF module has been used to transmit and receive the information between remote and robot and display the information related to the hurdle detection on LCD. The whole circuitry is connected with $12 \mathrm{~V}$ battery.
\end{abstract}

\section{Keywords}

LCD, KEYPAD, RF MODULE, IR SENSOR

\section{INTRODUCTION}

Robot is an electromechanical machine and used for various purposes in industrial and domestic applications. Robot appliances are entering in the consumer market, since the introduction of iRobots. Many related appliances from various companies have been followed. Initially the main focus was on having a cleaning device. As the time pass on many improvements were made and more efficient appliances were developed.

In early, 2010 a new automatic floor cleaner robot "Mint" was developed by Jen Steffen. Detachable clothes were attached for sweeping and mopping purposes. For tracking mint used the GPS-like indoor localization system.

In this research work a floor cleaner robot based on AT89S52 have been developed. This cleaner robot is an electric home appliance, which works in two modes as per the user convenience "Automatic and Manual". Unlike other floor cleaner robots this is not a vacuum cleaner robot; it performs sweeping and mopping operation. Detachable mop is used for mopping. It works on $12 \mathrm{~V}$ supply. In the automatic mode, robot performs all operations itself. Firstly robot starts it moves forward and perform cleaning action. For obstacle detection and to avoid hurdle IR sensors have been used. If any hurdle detected then robot change the lane automatically, does not stop and starts cleaning action. It follows zigzag path. To make whole system wireless, RF modules have been used in automatic and manual with $50 \mathrm{~m}$ range. For user convenience automatic water sprayer is attached which automatically spray water for mopping, therefore no need to attach wet cloth again and again for mopping. Motor driver circuit have been used to drive the motors. Four motors have been used to perform respected operations like to move the robot, for water pump, for cleaner. Relays have been used to drive the water pump and cleaner motor. LM293D IC has been used to drive wheel motor. All the information displayed on LCD.

In the manual mode, user itself operates the robot. RF module have been used to transmit and receive the signal to operate the robot through remote. In the manual mode, if any hurdle detected, then signal of hurdle detection displayed on the LCD of remote via RF module.

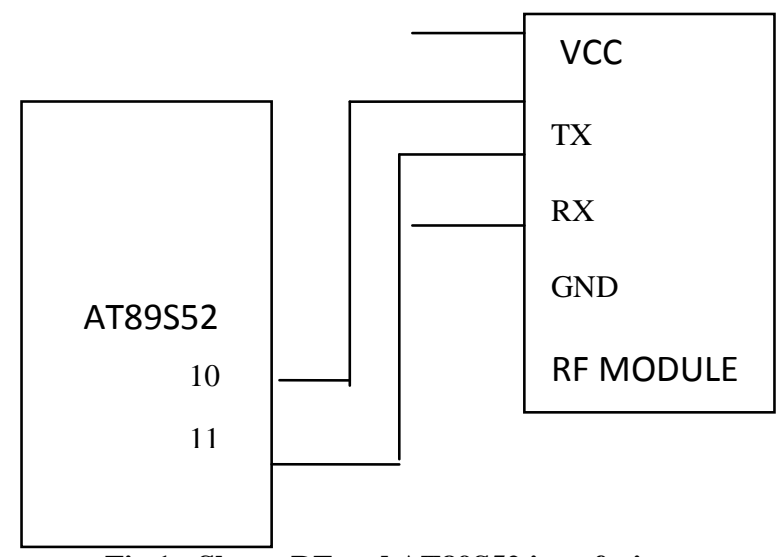

Fig 1: Shows RF and AT89S52 interfacing

Movement of robot is controlled by user itself through keypads therefore user can move the robot in the desired direction. All the information displayed on the LCD.

\section{RELATED WORKS}

In this paper, the mint cleaning robot which is an automatic cleaning robot that sweeps and mops hard-surface floors using dusting and mopping clothes was developed. It investigates the product's social impact with respect to the attitude of the customers towards a systematic floor cleaner and how such a robot influences their lifestyle. Systematic cleaning was an important feature, and modifications to the environment to support the navigation of robot. The robot employs a systematic cleaning strategy that maps the environment using a GPS-like indoor localization.[1]

In this paper autonomous and automatic home Mess-Cleanup robot (Mcbot) is newly developed. So far, the vacuum cleaner 
had made the burden of house core light and but the operational labor of a vacuum cleaner had been so severe. In this paper the RFID tags are used to sense the obstacle and propose the new disposition algorithm to have RFID tags installed on the floor and objects indoor. It needs to also have an intelligent interaction function for the human-friendly communication. RFID tags are installed to detect the obstacles which is costly and complex[2].

This paper presents a floor cleaning robot equipped with Swedish wheels. It can be used in crowded places such as houses, train station, airport etc.The robot can perform its work in autonomous mode. Moreover the robot can pivot around without turning, can avoid obstacles and is provided with automatic power management ability and meanwhile, the kinematics for its control and controlling methods are studied and demonstrated. This new structure, smooth locomotion capability and high working efficiency are verified by experimentation. Vacuum cleaning can be done by this robot and ultrasonic detections sensors are used for obstacle detection [3].

In this paper a new type of home intelligent cleaner adopted the ultrasonic and infrared sensor array, which has the function of the real-time environment perception, is introduced, and this cleaner driven by step motor has the ability of autonomous working by itself and the functions of the automatic detection and obstacle avoidance. This paper adopts grid scanning algorithm based on electric map realize floor coverage task, and designs synthesis detection system based on sensor arrays finding method technology according to algorithm characteristics, experimental results for obstacle detection by static finding indicates that the design detection systems improves cleaning robot's environment perception and path search ability greatly[4].

\section{BLOCK DIAGRAM}

The block diagram of this proposed research work "Design and development of floor cleaner robot (automatic and manual) has shown fig. 2 and 3 for better understanding of the proposed work. Block diagram consist of two parts: one for automatic (robot) and another for manual (remote) mode. The automatic part is integration of power (12V), AT89S52, LCD, RF modules, dual relay circuit, LM293D, IR sensors .AT89S52 is core of this system which controls all operations and energized with $5 \mathrm{~V}$ power. AT89S52 is used because of better features like: it is low power, high performance CMOS 8 bit microcontroller with $8 \mathrm{~K}$-bytes in-system programmable flash memory, 256 byte RAM, 32 I/O lines, full duplex serial port,16 bit timer/counter, on chip oscillator, and supports two software selectable power signal modes, low power idle and power-down mode. RF module provides wireless communication between remote and robot and operates at $5 \mathrm{~V}$ supply and its operating range is $50 \mathrm{~m}$. IR sensors used for obstacle detection. If any object appears in the robot way then IR sensor detect the object and send signal to microcontroller and buzzer beeps and robot change the lane automatically and then start cleaning operation again and its range is $1 \mathrm{ft}$ and it works on $12 \mathrm{~V}$ power. 5 motors are used in this system; 2 motor used to drive the wheels, 1 motor used for water pump and 2 motors used for cleaning action. DC gear motors are used to drive the robot. L293D IC used to drive the wheel motor because of better features like: 600ma output current capability per channel, 1.1A peak output current, inbuilt diodes, over temperature protection and having high noise immunity and it requires $12 \mathrm{~V}$ power to work. Dual $9 \mathrm{~V}$ relay circuit is used to drive the cleaner motor and water pump motor which is in normally open contact mode and works on
$9 \mathrm{~V}$ supply. Relay is used because of its efficient switching characteristics and has capability to control high voltage circuit with the help of low voltage circuit and also used where single circuit can control more than one circuits. In automatic part two batteries are used to operate the robot. Power supply consist of 1voltage regulator 7805 3PIN, 1 shunt capacitor (1000uf), 1 led indicator and a $1 \mathrm{~K}$ resistance. All the signals and results displayed on LCD.

Now the second part i.e. manual mode which is controlled by user itself and consist of power (12V), AT89S52, LCD, keypad, RF modules. AT89S52 is main part of the manual mode, all the signals controlled by microcontroller and it takes $5 \mathrm{~V}$ power to work. RF module is used to transmit and receive the signal. If any hurdle detected in the manual mode then robot send the signal through RF module of hurdle detection to remote. RF module has $50 \mathrm{~m}$ range and operating frequency $2.4 \mathrm{GHz}$. Keypad is used to give the direction to robot and user through keypad user can control all the operation like; movement of robot, cleaning action to on or off the cleaner and water pump etc. All the information displayed on LCD.

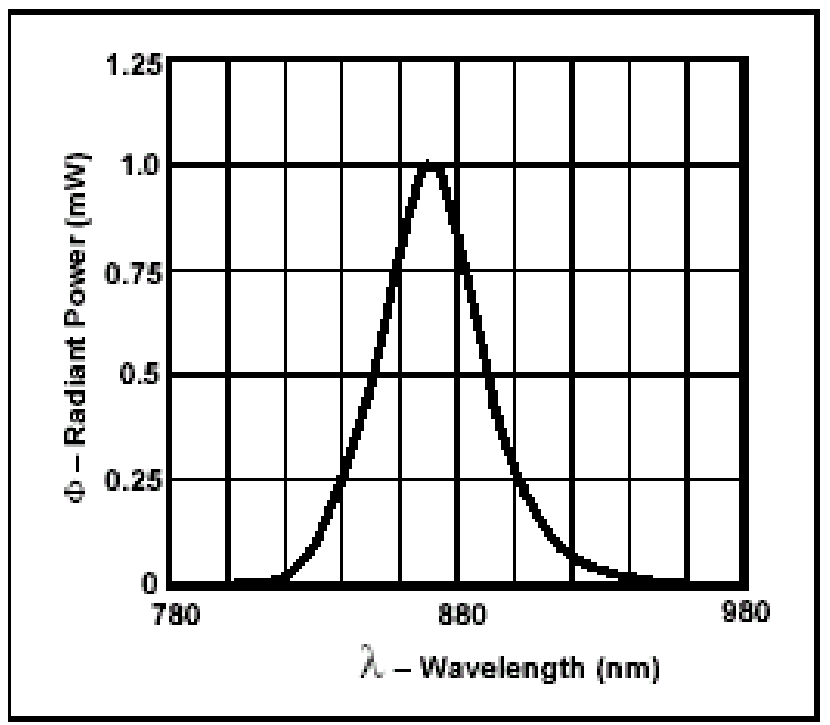

Fig 2 : Radiant Power vs Wavelenth of IR sensor 
Automatic Mode

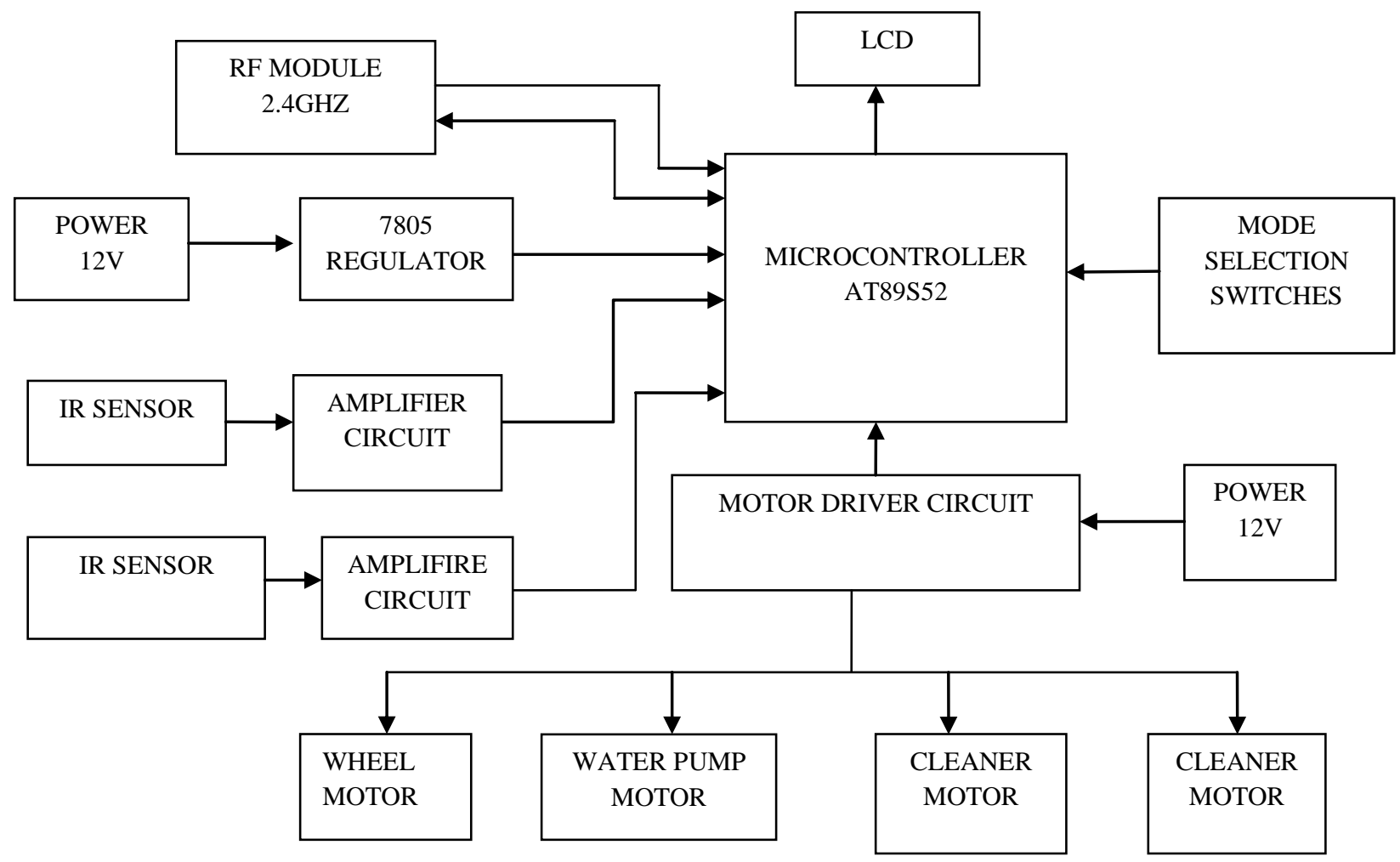

Manual mode

Fig.3: Automatic mode

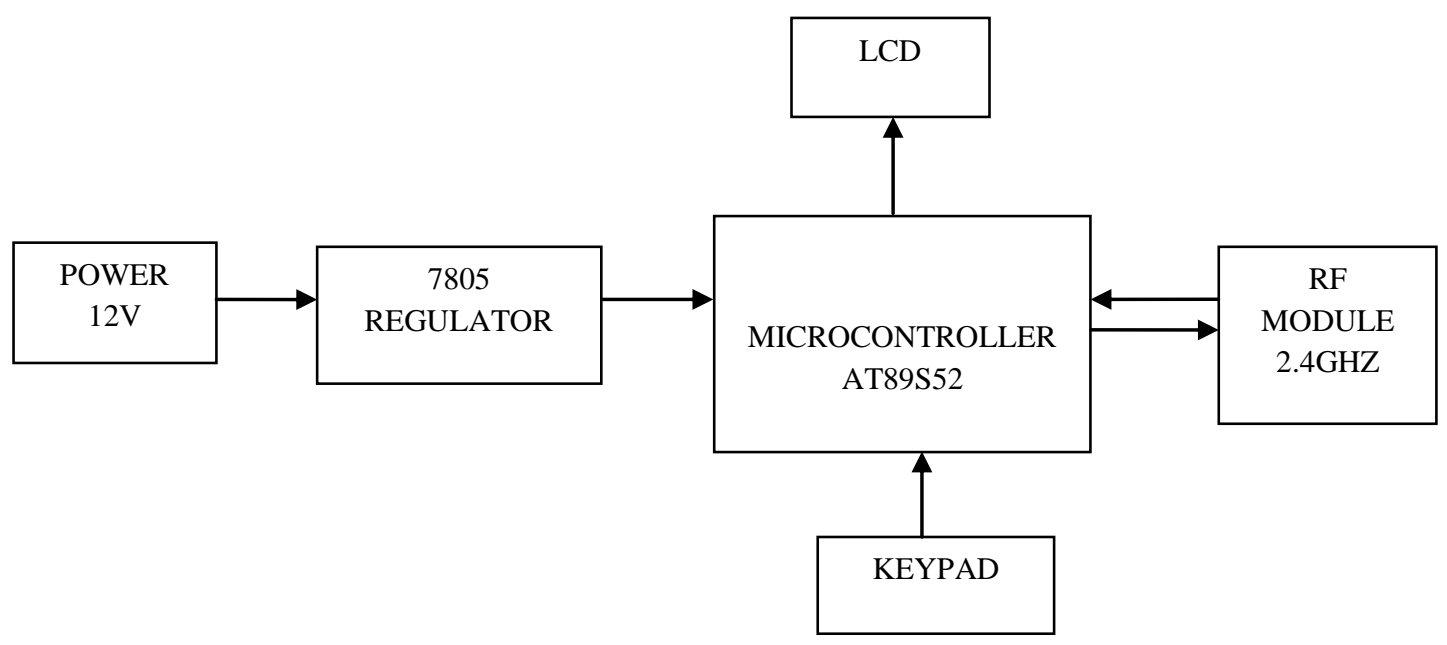

Fig.4 : Manual mode 


\section{SOFTWARE DESIGN}

\section{METHDOLOGY}

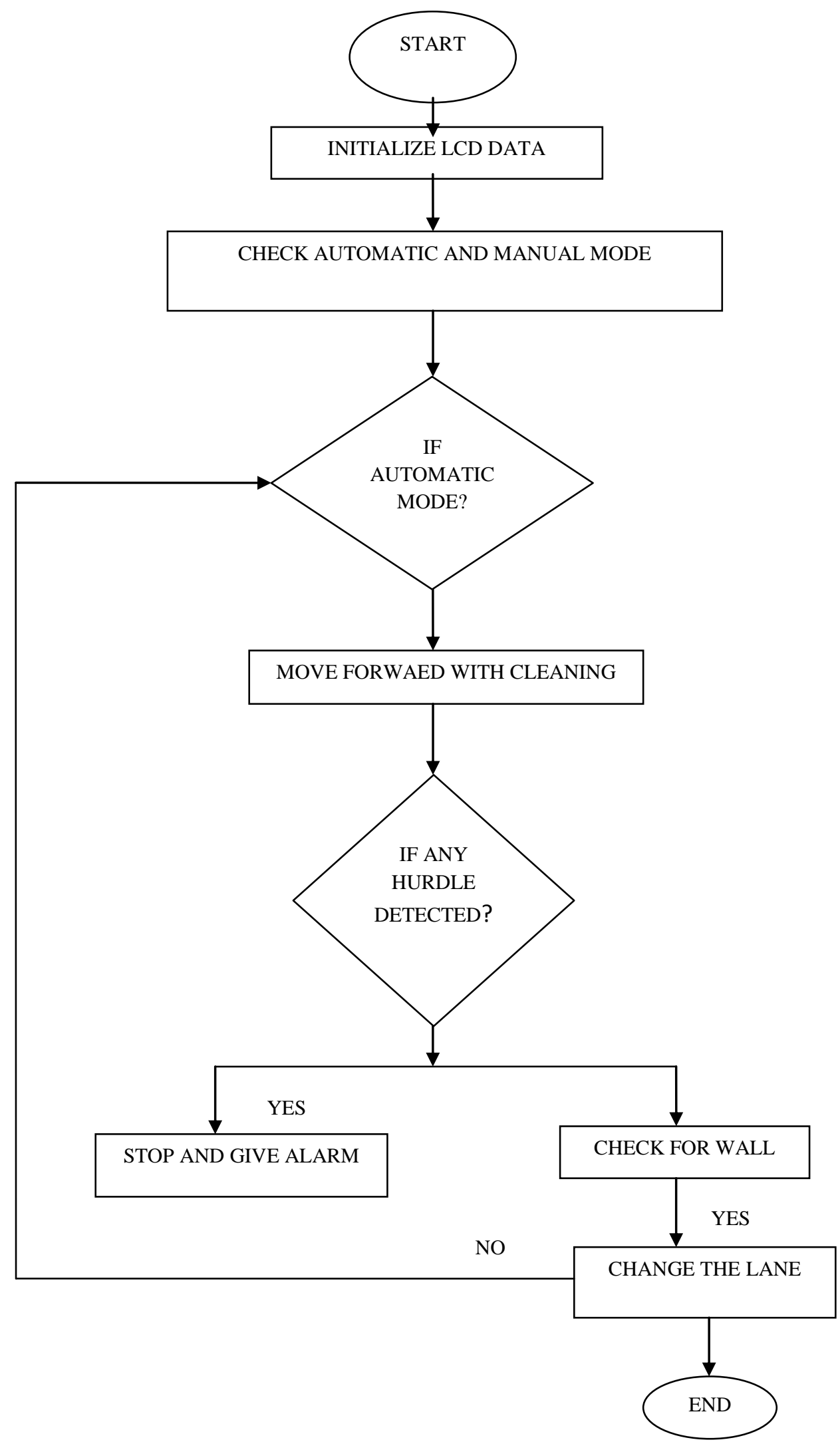

Fig 5: Shows software flow for automatic mode 


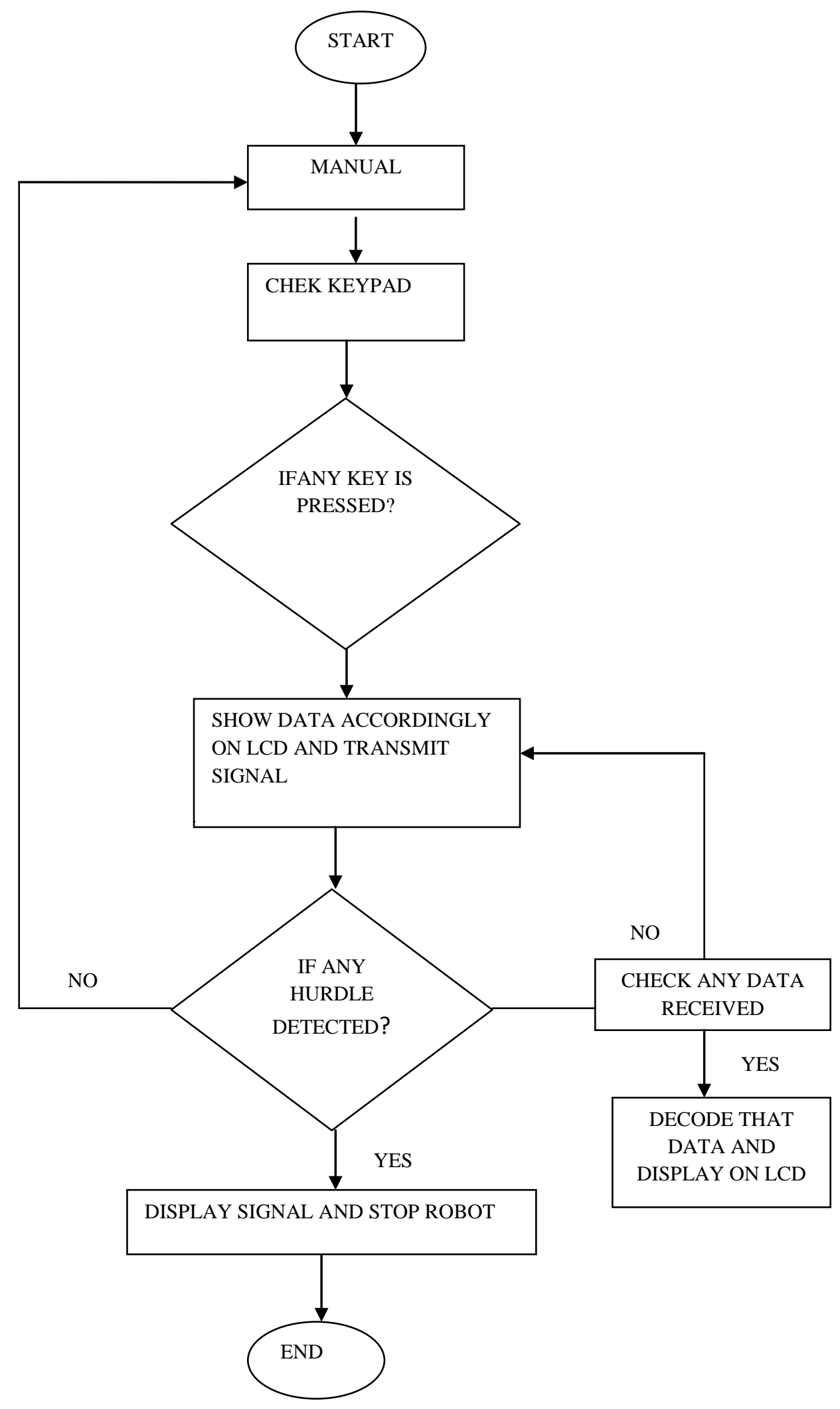

Fig 6 : Shows software flow for manual mode 
Fig 4 shows the software methodology of the floor cleaning robot. Firstly, software checks data is initialized or not. If data is initialized then it checks for which mode is selected, automatic or manual. There are two conditions now automatic and manual, if manual mode is selected then firstly, it checks data given to the robot and then control the robot according to given data. If any data received it will decode that data and show that data on LCD. After that two conditions arrive, if any hurdle detected then robot will send the stop and hurdle detection signal to the remote and if there is no hurdle it will work according to the given data. If automatic mode is selected then firstly, robot will start moving forward with cleaning action. After that if there is hurdle detected then it will stop and give alarm and moves back and start again, also check if there is wall then it turns and clean the further area.

\section{RESULTS AND DISCUSSION}

Firstly, when we switch on the robot, it asks for which mode we want to select i.e. automatic or manual. For automatic mode press "A" and for manual mode press "M" as shown in the fig7.

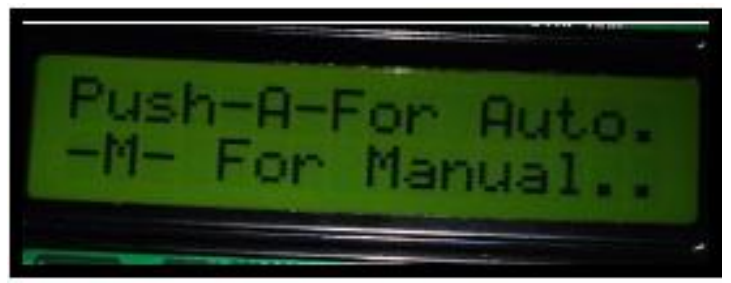

Fig 7: Shows the mode selection

Now auto mode is selected which is shown in fig 8 .

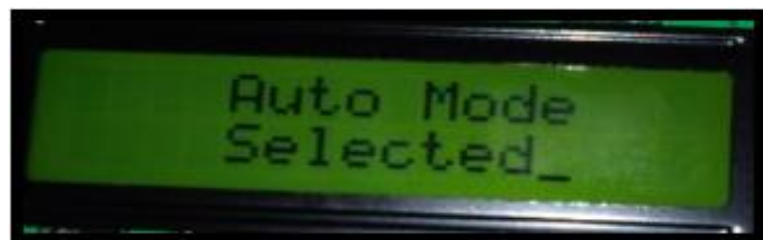

Fig 8: Shows auto mode is selected

After the auto mode has been selected robot will start doing cleaning operation automatically as shown in fig 9 .

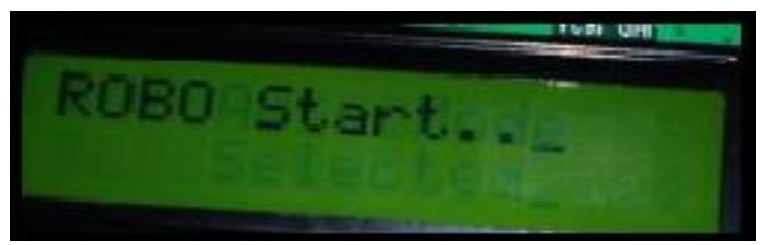

Fig 9: Shows that robot has been started and performs cleaning

Now manual mode has been selected as shown in the fig 10 . After manual mode selection user can robot as he/she want to operate in any direction as shown in above figures.

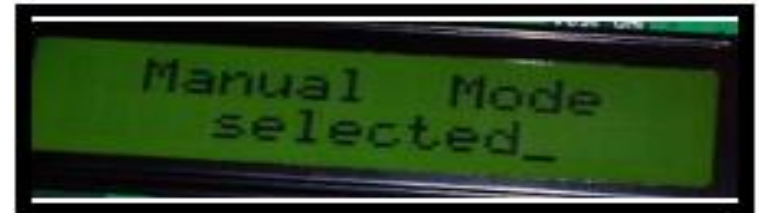

Fig 10: Shows manual mode is selected

After manual mode selection, the robot will start cleaning operation as the user wants to operate as shown in fig 11 . Robot will move in forward direction with water pump and cleaner on.

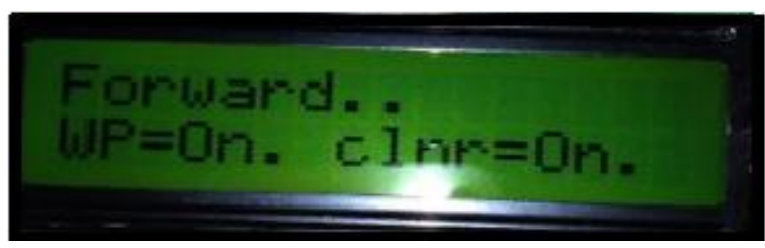

Fig 11: Shows the robot motion in forward direction

The fig. 12, shows the movement of robot in left direction with water pump on and cleaner on.

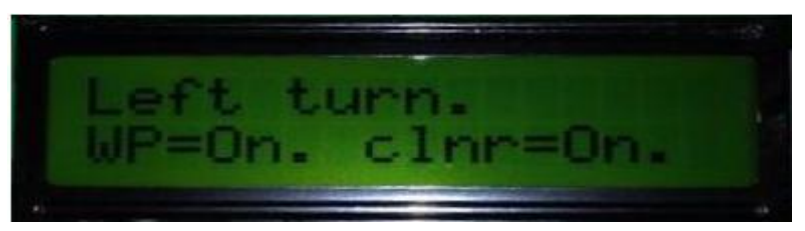

Fig 12: Shows the robot movement in left direction

Fig 13, shows robot moving in right direction with water pump off and cleaner on it depends on user whether on or off cleaner and water pump according to requirement.

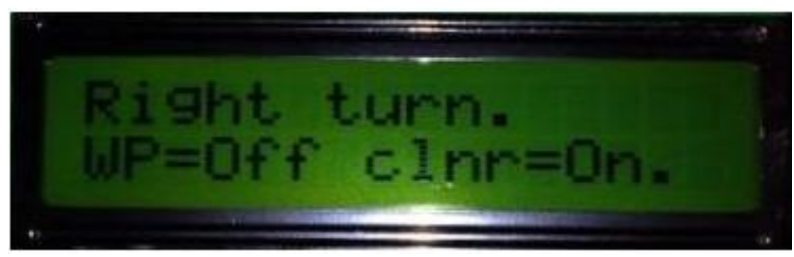

Fig 13: Shows the robot movement in rightt direction

Fig 14,shows the robot movement in reverse direction with cleaner on and water pump off.

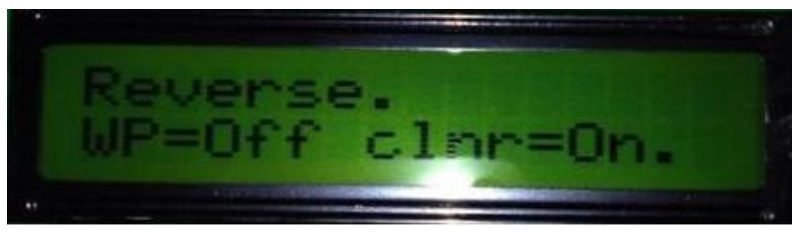

Fig 14: Shows the robot movement in right direction 


\section{CONCLUSION}

This research facilitates efficient floor cleaning with sweeping and mopping operations. This robot works in two modes automatic and manual for user convenience. This proposed work provides the hurdle detection in case of any obstacle that comes in its way. The obstacle detection range is $1 \mathrm{ft}$. RF modules provide wireless communication between remote and robot and their range is $50 \mathrm{~m}$. If there is hurdle in the way of robot, it sends the information to the remote which gets displayed on the LCD. An automatic water sprayer is attached which sprays water for mopping purpose for the convenience of user. User can also operate this robot manually with the help of remote. It reduces the labor cost and saves time also and provides efficient cleaning. In automatic mode, the robot operates autonomously. The operations such as sweeping, mopping and changing the path in case of hurdle are performed automatically.

Nonetheless, there are still new ideas to improve the developed system and to add new functionality to it. Instead of RF module, Xbee pro series module can be used to improve the range of wireless communication. GSM module can be used to send message that, the robot has done the cleaning task. Camera can be used for navigation purposes. Vacuum cleaning can also be done with sweeping and mopping. Further, the robot can be made to move randomly in any direction and its speed can be controlled.

Table 1. Comparison with previous work

\begin{tabular}{|c|c|c|c|}
\hline S.NO & Features & $\begin{array}{l}\text { Previous } \\
\text { Work }\end{array}$ & Present Work \\
\hline 1. & Cost & $\begin{array}{l}\text { More than } \\
10000 .\end{array}$ & Rs 10000. \\
\hline 2. & Keypad & $\begin{array}{l}\text { Not } \\
\text { available. }\end{array}$ & $\begin{array}{l}\text { Available to } \\
\text { operate robot } \\
\text { through remote } \\
\text { and for mode } \\
\text { selection. }\end{array}$ \\
\hline 3. & RF module & $\begin{array}{l}\text { Not } \\
\text { available. }\end{array}$ & $\begin{array}{l}\text { Available for } \\
\text { wireless } \\
\text { communication. }\end{array}$ \\
\hline 4. & $\begin{array}{l}\text { Automatic } \\
\text { water } \\
\text { sprayer }\end{array}$ & No & Yes \\
\hline 5. & LCD & $\begin{array}{l}\text { Not } \\
\text { available. }\end{array}$ & $\begin{array}{l}\text { Available for } \\
\text { displaying } \\
\text { authentication } \\
\text { results. }\end{array}$ \\
\hline 6. & IR Sensors & No. & $\begin{array}{ll}\text { Yes. } & \text { For } \\
\text { obstacle } & \\
\text { detection } & \text { and } \\
\text { avoidance. } & \\
\end{array}$ \\
\hline 7. & $\begin{array}{l}\text { Mode of } \\
\text { operation }\end{array}$ & $\begin{array}{l}\text { Only } \\
\text { automatic. }\end{array}$ & $\begin{array}{l}\text { Automatic and } \\
\text { manual both. }\end{array}$ \\
\hline
\end{tabular}

\section{ACKNOWLEDGMENT}

We are grateful to CDAC Mohali, to provide all facilities regarding research work and also grateful to MHRD , GOVT of India for providing us all facilities to carry out research work

\section{REFERENCES}

[1] Jens-Steffen Gutmann , Kristen Culp , Mario E. Munich and Paolo Pirjanian. The Social Impact of a Systematic Floor Cleaner. In IEEE international workshop on advance robotics an its social impacts, Technische University munchen, Germany May 21-23,2012.

[2]Evolution Robotics Inc. Introducing Mint-the evolution of floor care, www.mintcleaner.com, 2011.

[3]J-S. Gutmann, E.Eade, P.Fong and M.E. Munich. Vector field SLAM. IN Int. conf. on Robotics and automation (ICRA), 2010.

[4]J-Y. SUNG, R.E.Grinter, and H.I.Chrstensen, and L.Go.Housewives domestic robot technology int. Journal of social robotics, 2(4):417-429,2010.

[5]Youngkak Ma, seungwoo Kim, Dongik Oh and Youngwan Cho.A study on development of home mess- cleanup robot McBot.In IEEE/ASME international conference on advanced mechatronics July 2-5, 2008, Xian, China.

[6] Xueshan Gao, Kejie Li, Yan Wang, Guangliang Men, Dawei zhou and Koki Kikuchi. A floor cleaner robot using Swedish wheels.In IEEE international conference on robotics and biomimetics December 15-18, 2007, Sanya, China.

[7] G Tuangzhi Dai and Tiequn Chen.Design on measurement and control system of cleaning robot based on sensor array detetion.In IEEE International conference on control automation Guangzhou, CHINA-MAY 30 to June 1, 2007.

[8] J Frolizzi C.Disalvo. Service robots in the domestic environment: A study of Roomba vacuum in the home". In int. conference on human robot interaction HRI PAGE 258-265 March 2006.

[9] H.Asada and J.-J E. Slotin, robot analysis and control, a wiley-interscience publication, 1986, pp. 29-49. 